Research Article

www.jestr.org

\title{
Effect of Static-Dynamic Coupling Loading on Fracture Toughness and Failure Characteristics in Marble
}

\author{
Z. Q. Yin ${ }^{1,2, *}$, H. F. Ma ${ }^{3}$ Z. X. Hu ${ }^{1,2}$ and Y. Zou ${ }^{4}$ \\ ${ }^{1}$ The Provincial Key Laboratory of mining effects \& disasters preventing under deep mining in Anhui, \\ Anhui University of Science and Technology, Huainan, 232001-China \\ ${ }^{2}$ Sch. of Mineral \& Safety, Anhui University of Science and Technology, Huainan, 232001, China \\ ${ }^{3}$ Fac. of Resources \& Safety Engineering, China University of Mining and Technology, Beijing, 100083, China \\ ${ }^{4}$ Lab. for Rock Mechanics (LMR), École polytechnique fédérale de Lausanne (EPFL), Lausanne, CH 1015, Switzerland
}

Received 15 September 2013; Accepted 27 March 2014

\begin{abstract}
Fracture experiments in a notched semi-circular bend configuration were conducted to test the dynamic fracture toughness of a marble under static-dynamic coupling load using a modified split Hopkinson pressure bar. The fracture process of the specimen was monitored using a high speed (HS) camera. Based on digital image correlation (DIC) and strain gauges, the full-field strain fields and time-to-fracture of the marble were measured under static-dynamic coupling load. Experimental results show that dynamic fracture toughness was well determined, and the HS-DIC technique provides reliable full-field strain fields in the specimens under static-dynamic coupling loads. The failure characteristics of the marble under external impact were affected obviously by pre-compression stress. Increase of axial pre-compression stress was helpful to improve the crack propagation velocity, and dynamic crack initiation toughness was decreased.
\end{abstract}

Keywords: Static-dynamic coupling loading, Digital image correlation, SHPB, Dynamic fracture toughness, Failure mechanisms

\section{Introduction}

Tension is an important characteristic of rocks. Rocks under tension are much weaker than under compression, and thus the failure of rock structure is largely due to tensile stress. Thus, it is important to characterize the tensile strength of rocks generally and to understand the correlation between strength and microcrack induction [1].

In many rock engineering fields such as mining and civil engineering, besides static stress in circumstance of rock excavation, the surrounding rock is also under dynamic stress, such as rock cutting, tunneling, drilling, blasting, and rock bursts. The mechanic performances of rock between dynamic loads, static loads and static-dynamic coupling loads are significantly different [2, 3]. Researchers more fiercely study the transient response of rock failure under dynamic loads, and accurately describe the deformation and fracture characteristics in particular.

The SHPB (split-Hopkinson pressure bar) is widely used among all dynamic loading apparatuses. SHPB is a standard apparatus for measuring the mechanical properties of materials at strain rate between $10^{1}$ and $10^{4} \mathrm{~s}^{-1}$. In the present study, several dynamic testing methods such as notched semi-circular bending (NSCB) [4] and Brazilian disc (BD) [5] were conducted using a modified SHPB technique. The SHPB system combined with a high speed (HS) camera and the digital image correlation (DIC) technique provides reasonable and reliable determination of mechanical properties and is turning to the main stream to investigate the microstructure and failure micromechanics of materials under dynamic loads [6].
In this work, the mechanical properties of marble specimens under static-dynamic coupling load were characterized using the modified SHPB device, and then the fracture process was monitored using an HS camera. Based on DIC and strain gauges (SGs), the full-field strain fields and time-to-fracture of the specimens were measured under static-dynamic coupling load. Dynamic crack propagation velocity, crack initiation toughness and failure mode were well determined.

\section{Principle of DIC}

DIC operates through the mathematical comparison of two sub-images from a pair of larger displaced images [7, 8]. To determine the distortion of a small region, the primary assumption of DIC is that the essential characteristics of the speckle pattern remain the same before and after deformation. DIC uses the correlation coefficient $\mathrm{C}$ as a description parameter [9], which is calculated as:

$$
C(u, v)=\frac{\sum_{y=1}^{y=n} \sum_{x=1}^{x=m} f\left(x_{i}, y_{i}\right) \cdot g\left(x_{i}, y_{i}\right)}{\sqrt{\sum_{y=1}^{y=n} \sum_{x=1}^{x=m} f\left(x_{i}, y_{i}\right)^{2} \cdot \sum_{y=1}^{y=n} \sum_{x=1}^{x=m} g\left(x_{i}, y_{i}\right)^{2}}}
$$

where $\left(x_{i}, y_{i}\right)$ are the Cartesian coordinates of the resource and the target points located in the reference and deformed images, respectively; $f\left(x_{i}, y_{i}\right)$ and $g\left(x_{i}, y_{i}\right)$ are the grey values

\footnotetext{
*E-mail address: zhqyin@aust.edu.cn 
of the subset in the reference and deformed images, respectively.

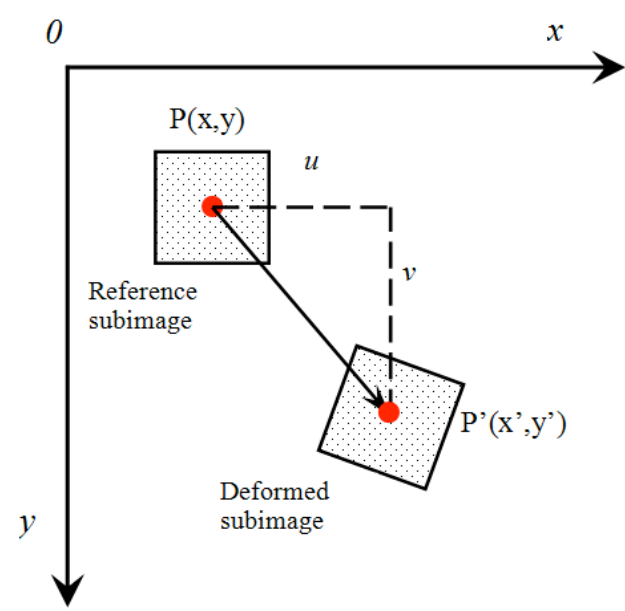

Fig. 1. Schematic drawing of relative location of sub-images of deformed and reference images on surface

The magnitude of $\mathrm{C}$ varies from 0 to 1 , where 1 signifies a perfect match between two images. When deformation occurs on the specimen's surface within a small region, the local characteristics of the speckle images are changed, and $\mathrm{C}$ becomes smeller than in other apparently deformed areas. In this paper, $C$ is much more than 0.95 in the area of interest, indicating that the two speckle images captured before and after deformation matched well.

\section{Experimental Setup}

\subsection{The dynamic test system}

The modified SHPB system was used for impact tests under triaxial pre-pressure (Fig.2). The stress transmission component consists of two long elastic bars (input bar and output bar). The elastic bars are $2 \mathrm{~m}$ in length and $50 \mathrm{~mm}$ in diameter. A specimen to be tested was sandwiched between the two elastic bars [10].

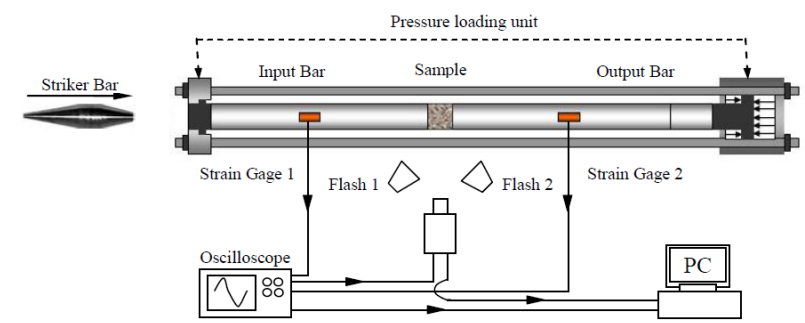

Fig. 2. Schematic of the SHPB system

A conical bullet was used in the modified test system to eliminate oscillation and obtain a stable half-sine wave load [11]. The bullet's material quality and the projectile body's maximum diameter are the same as those of the input and output bars. The stress waves were recorded with a CS-1D super dynamic meter and a DL750 oscilloscope (Yokogawa).

\subsection{Data acquisition and processing}

Strain gauges (SGs) were glued on the surface between the elastic bars and used to measure the historic strains induced by the stress waves propagating along the elastic bars. The
SGs were located ideally when the incident and reflected waves did not overlap (Fig. 3) [12].

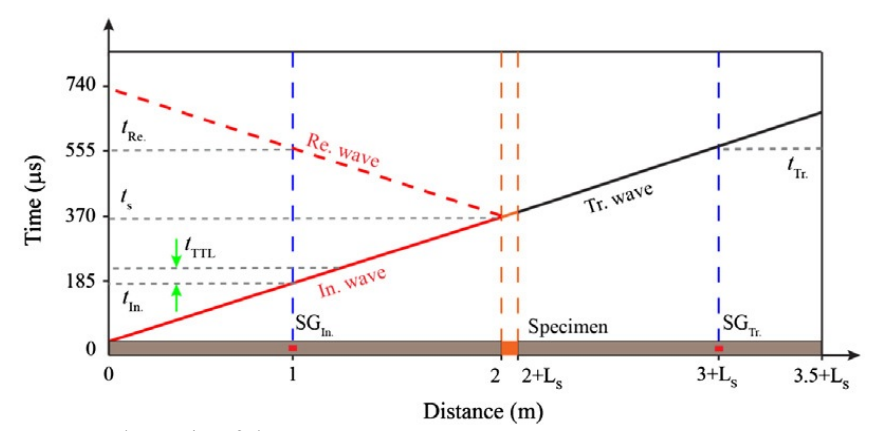

Fig. 3. Schematic of the SHPB system

The ramped waves produced by the cone-shaped striker prolonged the rise time of the incident stress wave and thus allowed the specimen to equilibrate during the time of interest for the test. Since the strains in the elastic bars are known, the normal forces at the two bar/ specimen interfaces can be calculated as:

$P_{1}=E_{\mathrm{b}} A_{\mathrm{b}}\left(\varepsilon_{\mathrm{I}}+\varepsilon_{\mathrm{R}}\right) \quad P_{2}=E_{\mathrm{b}} A_{\mathrm{b}} \varepsilon_{\mathrm{T}}$

where $E_{\mathrm{b}}$ is the Young's modulus of the bar, $A_{\mathrm{b}}$ is the cross-sectional area of the bar, and $\varepsilon_{\mathrm{I}}, \varepsilon_{\mathrm{R}}$ and $\varepsilon_{\mathrm{T}}$ are the incident, reflected and transmitted strains measured by SGs on the bars respectively.

The typical approach to check stress equilibrium involves a comparison of the force histories at the two sides of the specimen. If the forces are nearly equal, the specimen is in stress equilibrium. The mean force applied on the specimen can be derived as:

$$
P(t)=\frac{1}{2}\left(P_{1}+P_{2}\right)-\frac{1}{2} E_{\mathrm{b}} A_{\mathrm{b}}\left(\varepsilon_{\mathrm{I}}+\varepsilon_{\mathrm{R}}+\varepsilon_{\mathrm{T}}\right)
$$

\subsection{HS camera system}

In this work, the failure process of specimens was photographed using a PHOTRON FASTCAM SA1.1 HS camera, coupled with a PALLITE high-strength and nonstroboscopic light source and a Kenko PRO macro-lens with $2.0 \times$ objective lens, positioned $0.5 \mathrm{~m}$ away from the specimen's surface. The parameters were set as: frame-rate of $125,000 \mathrm{fps}$, image resolution of $256 \times 128$ pixels, and a shutter speed of $1 \mu \mathrm{s}$. The specimen was speckled with black and white paint.

A triggering system is composed of SGs (one on the surface of the input bar) and the oscilloscope. When the bullet hits the input bar, the stress wave is produced and propagating in the input bar. A through-the-len (TTL) electrical signal feasible for triggering will be generated when the oscilloscope records this stress wave signal by SGs. Therefore, the time of capturing HS-images started from the time triggered by the TTL pulse, and the number of captured images was obtained until the stress wave arrived at the specimen as follows:

$n=\frac{t_{\mathrm{s}}-t_{\mathrm{In}}-t_{\mathrm{TTL}}}{t_{\text {frame }}}$ 
where $t_{\mathrm{s}}$ is the time-of-arrival of the specimen, $t_{\mathrm{In}}$ is the time-of-arrival of the incident wave, $t_{\mathrm{TTL}}$ is the time triggered by a TTL pulse determined from the incident wave data (Fig. 3), and $t_{\text {frame }}$ is the inter-frame time of the HS camera.

\subsection{NSCB test methods}

The rock material used in the study was fine-grained marble available in Fangshan of Beijing. Each NSCB test specimen was made into the dimensions of 50 (diameter) $\times 20$ (thickness) mm (Fig. 4).

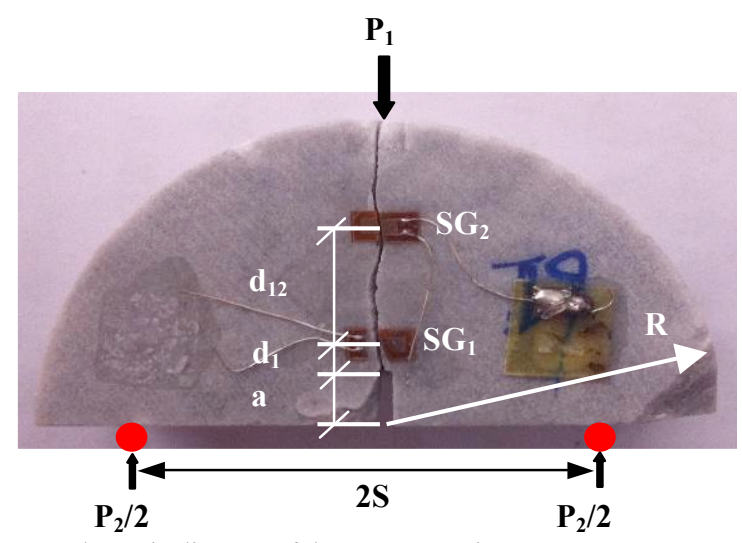

Fig. 4. Schematic diagram of the NSCB specimen

Specimen dimensions are $2 S=33.3 \mathrm{~mm}, R=25 \mathrm{~mm}, a=$ $5 \mathrm{~mm}$, and $B=20 \mathrm{~mm}$. The disk was then split along the diameter into two semi-circular specimens using an HS diamond impregnated circular blade (about $0.3 \mathrm{~mm}$ thick). An edge notch of $5 \mathrm{~mm}$ in length was cut and then the notch tip was sharpened using a diamond wire saw (about $0.1 \mathrm{~mm}$ thick) so as to obtain a sharp crack tip. The non-parallelism and the non-perpendicularity of the specimen were both less than $0.02 \mathrm{~mm}$. The specimen's surface is gray and smooth, with no distinct interspace. In this test, two SGs were located along the specimen's centerline, SG1 was placed $2 \mathrm{~mm}\left(\mathrm{~d}_{1}\right)$ away from the crack tip, and SG2 was placed $10 \mathrm{~mm}\left(\mathrm{~d}_{12}\right)$ away from SG1 (Fig. 4).

In dynamic tests, the dynamic stress intensity factor (SIF, $K_{\mathrm{I}}^{\mathrm{dyn}}$ ) of an NSCB specimen is expressed as [13]:

$$
K_{\mathrm{I}}^{\mathrm{dyn}}=Y_{\mathrm{I}}(S / R) \frac{P(t) \sqrt{\pi a}}{2 R B}
$$

where $Y_{\mathrm{I}}(S / R)$ is the Mode I geometry factor, $P(t)$ is the mean force applied on the specimen, $a$ is the crack length, $R$ is the specimen radius, $2 S$ is the span of the specimen, and $B$ is the specimen's thickness. For $a / R=0.2$ and $S / R=0.667, Y_{\mathrm{I}}(S / R)$ can be expressed as [14]:

$$
Y_{\mathrm{I}}(S / R)=3.638-0.139(a / R)+0.039 \exp [7.387(S / R)]
$$

The dynamic crack initiation toughness $\left(K_{\mathrm{Id}}\right)$ is then obtained from $K_{\mathrm{I}}^{\text {dyn }}$ at the time-to-fracture $\left(t_{\mathrm{f}}\right)$

$$
\begin{aligned}
& K_{\mathrm{Id}}\left(K_{\mathrm{I}}^{\mathrm{dyn}}\right)=K_{\mathrm{I}}^{\mathrm{dyn}}\left(t_{f}\right)=Y_{\mathrm{I}}(S / R) \frac{P\left(t_{f}\right) \sqrt{\pi a}}{2 R B} \\
& \text { Then } t_{\mathrm{f}} \text { is expressed as: }
\end{aligned}
$$

$t_{f}=t_{1 f}-t_{1}=t_{1 f}-\frac{d_{1}}{v_{1}}$

where $t_{1 f}$ is the time to fracture of SG1, $t_{1}$ is the time of crack propagating from the crack tip to SG1, $d_{1}$ is the distance between the crack tip and SG1 $\left(d_{1}=2 \mathrm{~mm}\right.$ in this test), and $v_{1}$ is the crack propagation velocity at the crack tip .

\subsection{Test process}

Firstly, the axial pre-compression stress $\left(S_{p c}\right.$, in accordance with the electric potential $U_{12}$ between SG1 and SG2 of 0 , 0.04 and 0.07 volts separately) was loaded on the rock specimen (Fig. 5). Evidently, the electric potential of SG1 was improved with the increasing axial $S_{p c}$, reflecting that the axial $S_{p c}$ subjected the crack tip under tensile stress, and the tensile stress was improved with the increasing axial $S_{p c}$ (Fig. 5).

Secondly, the axial impact loading was imposed, and during the test, the striker's position and the gas gun's air pressure were unchanged, and thus the speed of a strike was unchanged in test of different specimens.

Then the dynamic crack initiation toughness $\left(K_{I d}\right)$ and crack propagation velocity $(v)$ under varying tensile stress field were obtained and studied separately.

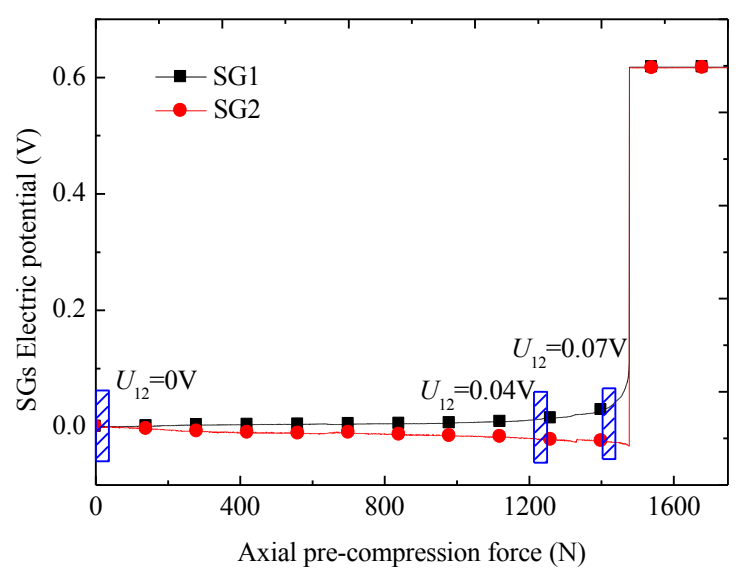

Fig. 5. Relation between load and electric potential under static loading

\section{Results and Discussions}

\subsection{Failure mode}

Figure 6 represents the results of a typical test with a striking velocity of $2.8 \mathrm{~m} / \mathrm{s}$ and the electric potential $\left(U_{12}\right)$ of 0.071 volts between SG1 and SG2. The magnitude of the partial data of SGs is shown in Fig. 7. The stress variation across the sample input and transmission terminal under dynamic loading is shown in Fig. 8. Clearly, the time of stress equilibrium before the fracture was about $60 \mu$ s (Fig. 8). To obtain satisfactory results, a prerequisite for determination of dynamic fracture toughness by the quasi-static theory was that the specimen was in stress equilibrium. 


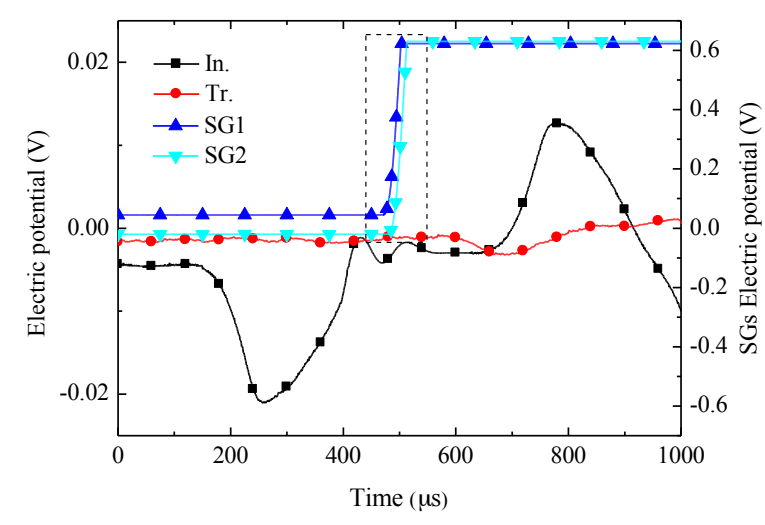

Fig. 6. Raw data of a typical NSCB test.

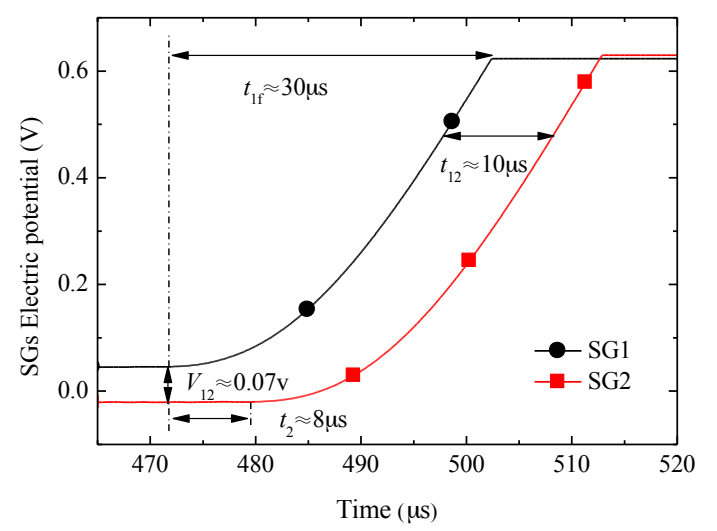

Fig. 7. Magnitude of the partial data of strain gauges.

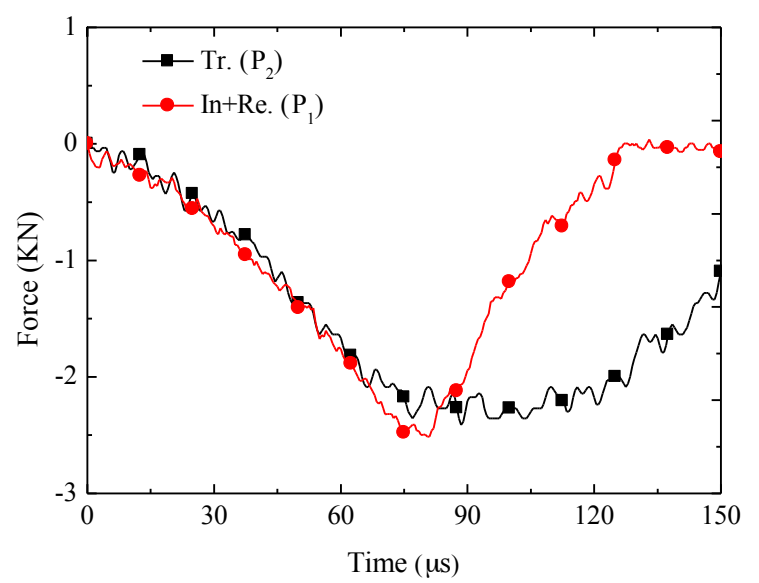

Fig. 8. Dynamic force balance check for dynamic NSCB test.

Figure 9 shows the dynamic photographs of crack propagation of the samples, which were obtained by recording the test process using the HS camera. Clearly, a white stripe was developed from the pre-crack tip to the specimen's boundaries along the loading direction on the specimen under impact loading (shown by dotted arrow), with the prolonged loading time, the crack initiated at about $32 \mu \mathrm{s}$, a white stripe gradually evolved into the macroscopic observable crack (position of crack tip showed by solid arrows).

\subsection{Fracture characteristics}

The time to fracture of SG1 $\left(t_{l f}\right)$ was about $30 \mu$ s and the time of crack propagating from SG1 to SG2 $\left(t_{12}\right)$ was about $10 \mu \mathrm{s}$ (Fig. 7). The distance between SG1 and SG2 was $10 \mathrm{~mm}$, and thus the crack propagation velocity $\left(v_{12}\right)$ between SG1 and SG2 was about $1000 \mathrm{~m} / \mathrm{s}$.

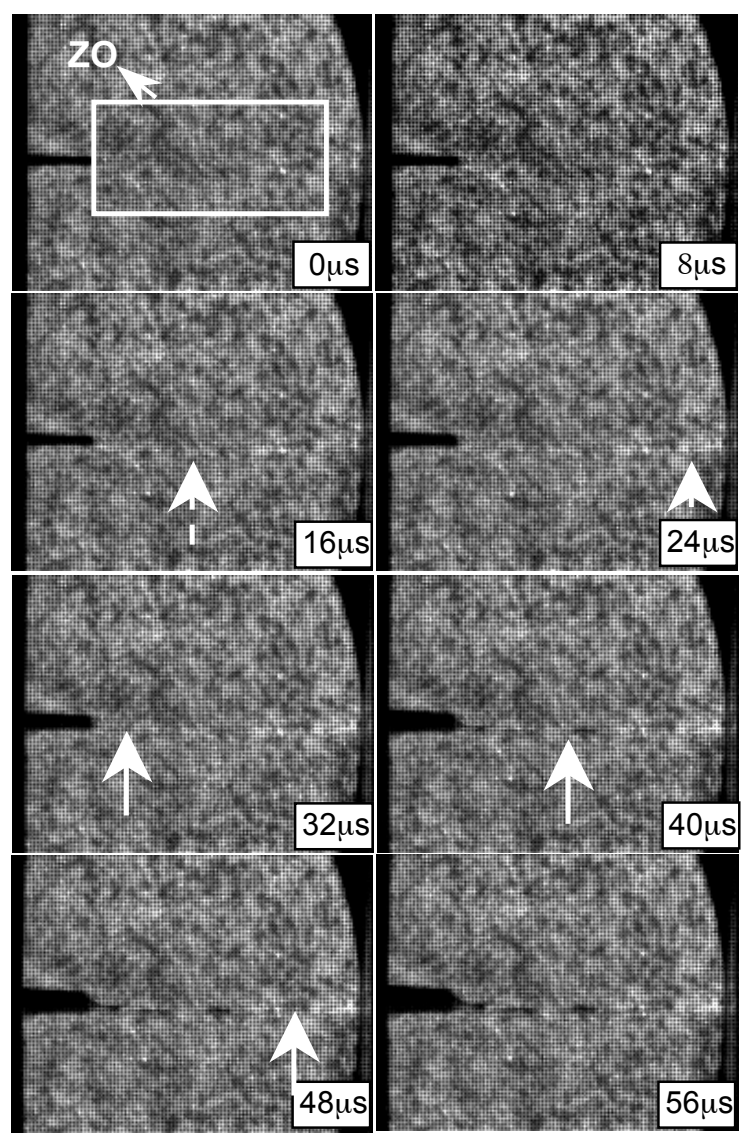

Fig. 9. HS-images at different stages

By the DIC processing of HS camera images, the crack velocity can be also calculated. In Fig. 9, with the first image $(0 \mu \mathrm{s})$ as the reference image, the zone-of-interest (ZOI) was selected for correlation calculation, which contained $150 \times 95$ pixels, the pixel size was equal to about $0.12 \mathrm{~mm}$ in the specimen. The calculation results of vertical strain field are shown in Fig. 10.

The results of vertical strain show that the maximum vertical strain fields were concentrated in the front tip precrack notch, while the maximum linear strain field was concentrated in the front tip pre-crack notch. Moreover, the value and size of strain increased with the impact loading time. According to the position of crack tip (vertical strain 0.1 ), the corresponding time of crack propagation velocity was calculated (Fig. 10). The crack position and speed and the corresponding time are shown in Fig.11. The crack propagation velocity was $1010 \mathrm{~m} / \mathrm{s}$ at the time of crack formation, and then slowed down with the crack expansion. In this study, the crack propagation velocity $\left(v_{12}\right)$ was used to estimate the crack propagation velocity at crack tip $\left(v_{1}\right)$.

Thus, the time to fracture $t_{f}$ with a striking velocity of $2.8 \mathrm{~m} / \mathrm{s}$ and the electric potential $\left(U_{12}\right)$ between SG1 and $\mathrm{SG} 2$ of 0.071 volts could be obtained from equationof $t_{f}: t_{f}=$ $t_{l f}-d_{1} / v_{12}=30-2 / 1.01 \approx 28 \mu \mathrm{s}$.

By the HS-DIC method, the crack propagation velocities from some experiments under varying $U_{12}$ were also calculated and plotted as a function of time (Fig. 11). The results show that the crack propagation velocity increases with the increasing $U_{12}$ and the fracture initiation time advance of the increasing $U_{12}$, which reflects that 
increase of the axial pre-compression stress $\left(S_{p c}\right)$ is helpful to improve the crack propagation velocity.

The evolution and determination of $K_{I}^{d y n}$ under axial $S_{p c}$ are shown in Figs.12 and 13. $K_{I}^{d y n}$ was weakened almost curvilinearly with increasing $U_{12}$ within 0 to 0.07 volts (Fig. 13). Comparison of $K_{I}^{d y n}$ under varying axial $S_{p c}$ and static fracture toughness [6] $\left(K_{I C}=1.5 \mathrm{MPa} \cdot \mathrm{m}^{1 / 2}\right)$ shows that, $K_{I}^{d y n}$ was higher than static fracture toughness with the absence of axial $S_{p c}$. With the increase of axial $S_{p c}, K_{I}^{d y n}$ decreased and was even lower than the static fracture toughness. This result shows that $K_{I}^{d y n}$ decreases with the increasing axial $S_{p c}$. Therefore, rock failure caused by the low impact energy under static-dynamic coupled loads with high $S_{p c}$.
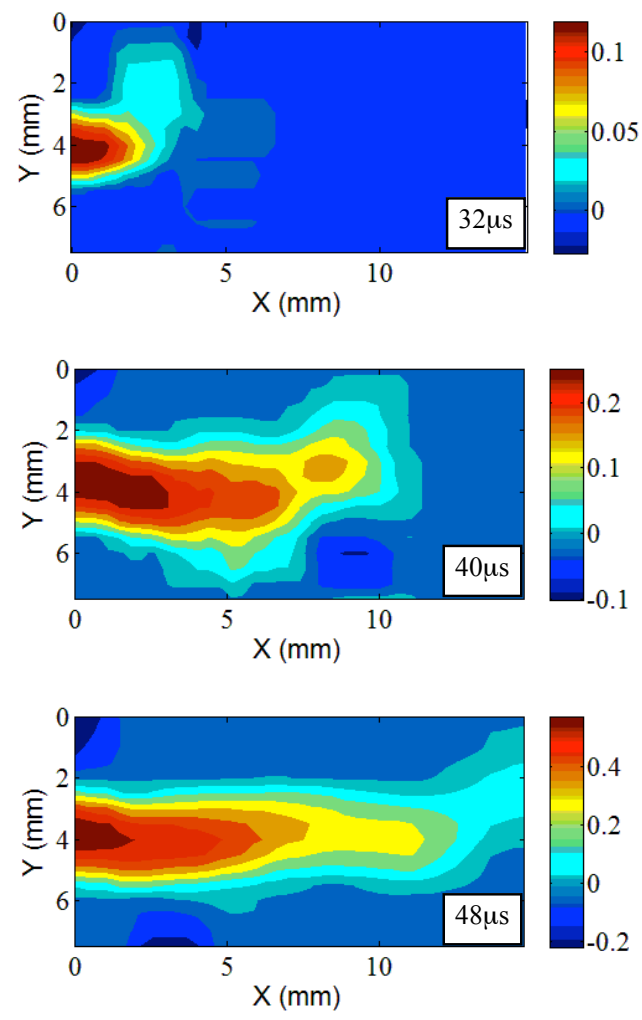

Fig. 10. HS-images at different stages

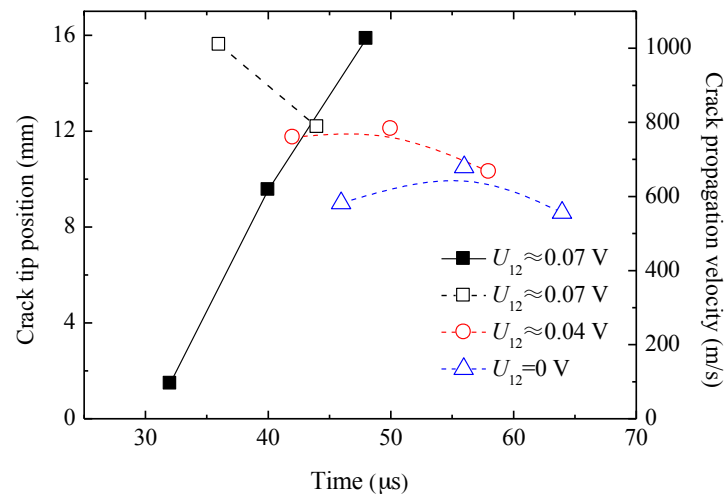

Fig. 11. Crack tip position and crack propagation velocity

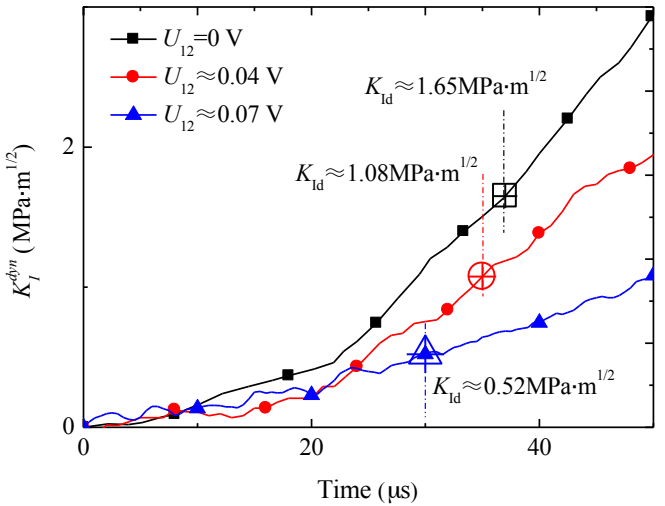

Fig. 12. Evolution of dynamic SIF and determination of $K_{I}^{d y n}$ under axial pre-compression stress

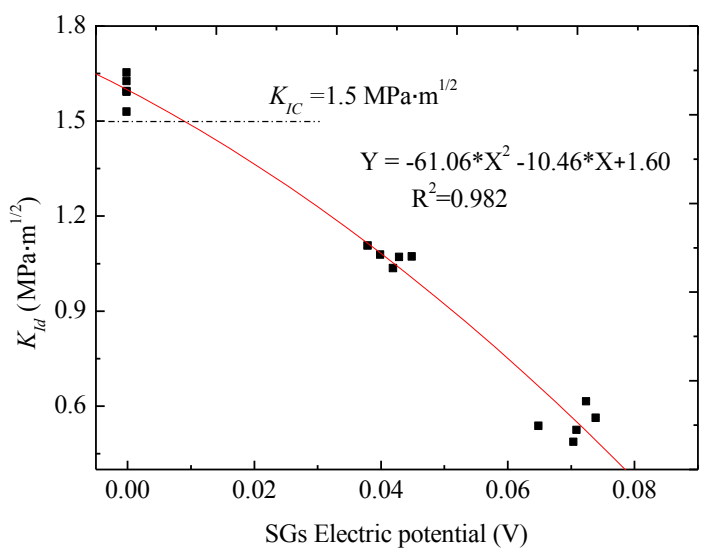

Fig. 13. Relation between $K_{I}^{d y n}$ and axial pre-compression stress under static-dynamic coupling load

\section{Conclusions}

The dynamic fracture toughness of the Fangshan marble under axial pre-compression stress was measured by using a modified SHPB system. Based on laboratory investigations and results obtained in this study, the following conclusions are drawn:1) The dynamic mechanic characteristics test under axial pre-compression stress with the half sine wave provides better stress loading, but the experimental results were ideal only if the sample was in equilibrium of dynamic load. 2) Comprehensive real-time measurement techniques such as strain gauges and high-speed DIC technique provided more accurate results on measurement of fracture time, full-field strain fields, crack propagation velocity and the history of crack opening displacement. 3) The failure characteristics of marble under external impact were affected obviously by pre-compression stress. Improvement of axial pre-compression stress was helpful to improve the crack propagation velocity and decrease the dynamic crack initiation toughness, even lower than static fracture toughness.

\section{Acknowledgments}

This research is supported by the National Natural Science Foundation of China (NO. 51304007, 51104004, 51104068), the State Key Program of National Natural Science Foundation of China (U1361208), Project funded by China Postdoctoral Science Foundation (NO. 2013M531495), 
Scientific Research Fund for Young Teachers of Anhui University of Science and Technology (NO. 2012QNY39) and Scientific Research Fund for Doctor and Master of Anhui University of Science and Technology.

\section{References}

1. Li, X.B., Gong, F.Q., "Test study of impact failure of rock subjected to one-dimensional coupled static and dynamic loads", Chinese Journal of Rock Mechanics and Engineering, 29(2), 2010, pp. 251-260. (In Chinese)

2. Yin, Z.Q., Li, X.B., "Failure characteristics of high stress rock induced by impact disturbance under confining pressure unloading", Transactions of Nonferrous Metals Society of China, 22(1), 2012, pp. 175-184.

3. Li, X.B., Zhou, Z.L., "Innovative testing technique of rock subjected to coupled static and dynamic loads", International Journal of Rock Mechanics and Mining Science, 45(5), 2008, pp. 739-748.

4. Dai, F., Xia, K., Tang, L., "Rate dependence of the flexural tensile strength of Laurentian granite", International Journal of Rock Mechanics and Mining Science, 47(3), 2010, pp. 469-475

5. Zhou, Z. L., Zou, Y., "Stress evolution and failure process of Brazilian disc under impact", Journal of Central South University of Technology, 20(1), 2013, pp. 172-177.

6. Zhang, Q. B., Zhao, J., "Effect of loading rate on fracture toughness and failure micromechanisms in marble". Engineering Fracture Mechanics, 102(4), 2013, pp. 288-309.

7. Zhou, Z.B., Chen, P.W., "Experimental study on the micromechanical behavior of a PBX simulant using SEM and digital image correlation method". Optics and Lasers in Engineering, 49(3), 2011, pp. 366-371.
8. Gu, R., Chen, S. and Wang, J, "A Novel Spectral Clustering and its Application in Image Processing”, Journal of Engineering Science and Technology Review, 4(1), 2011, pp.68-73.

9. Pierron, F., Sutton, M.A., "Ultra high speed DIC and virtual fields method analysis of a three point bending impact test on an aluminium bar", Experimental Mechanics, 51(4), 2010, pp. 537563.

10. Gong, F.Q., Li, X.B., "Experimental study of dynamic characteristics of sandstone under one-dimensional coupled static and dynamic loads", Chinese Journal of Rock Mechanics and Engineering, 29(10), 2010, pp. 2076-2085. (In Chinese)

11. LI, X. B., LOK, T. S., ZHAO, J., et al, "Oscillation elimination in the Hopkinson bar apparatus and resultant complete dynamic stress strain curves for rocks", International Journal of Rock Mechanics and Mining Science, 37(7), 2000, pp. 1055-1060.

12. Zhang, Q. B., Zhao, J., "Effect of loading rate on fracture toughness and failure micromechanisms in marble", Engineering Fracture Mechanics, 102(8), 2013, pp. 288-309.

13. Chong K. P., Kuruppu M. D., "New specimen for fracture toughness determination for rock and other materials", International Journal of Fractal, 26(2), 1984, pp. 59-62.

14. Lin, I. L., Johnston, I. W., Choi, S. K., "Stress intensity factors for semi-circular specimens under three-point bending", Engineering Fracture Mechanics, 44(3), 1993, pp. 363-82. 